\title{
The effect of correlated climatic factors on the radial growth of eucalypt trees grown in coastal Zululand of South Africa
}

\author{
Sileshi F. Melesse* and Temesgen Zewotir \\ School of Mathematics Statistics and Computer Science, University of KwaZulu-Natal, South Africa. \\ Accepted 28 December, 2012
}

\begin{abstract}
Understanding the relationship between stem radial growth and climatic conditions in plantation productivity is important to identify the climatic factors that most influence tree growth. This study aims to determine the climatic factors that most influence the stem radial growth of eucalypt trees plantation in the coastal Zululand area of South Africa. Daily stem radius was measured using automated point dendrometers located on 18 sample trees of Eucalyptus grandis $\times$ Eucalyptus urophylla (GU) and $E$. grandis $\times$ Eucalyptus camaldulensis (GC) hybrid clones. Daily averages of climatic data (temperature, solar radiation, relative humidity and wind speed) and total rainfall were also obtained from the site over the study period. Several statistical models that cope with the issue of multicollinearity were applied. Weather variables, together with tree age, explained a substantial amount of the variation ( $87 \%$ for GC clone and $79 \%$ for GU clone) in the daily stem radius. This study indicates that tree age is the most important factors that influence stem radius during the juvenile stage (up to 2 years) in all seasons. In winter, temperature, relative humidity and wind speed appear to be more important than the other weather variables.
\end{abstract}

Key words: Tree radial growth, latent variables, multicollinearity, ordinary least squares, partial least squares, principal component regression, plantation.

\section{INTRODUCTION}

Increasingly, eucalypts have become the most widely planted hardwood species in the world (Turnbull, 1999). At present, eucalypts provide sawn timber, mine props, pulp and paper, fiberboard, poles, firewood, charcoal, essential oils, nectar for honey, tannin, shade, and shelter. Most eucalypt plantations are established and managed for profit. The rate of growth is an important economic factor, and plantations with faster growth will be available for processing earlier compared with slower growth plantations. Tree growth and wood production are product of the interaction between genetic and environmental factors (Callaham, 1962). Some studies have found significant effects of environmental factors on wood property variation in Eucalyptus (February et al., 1995; Searson et al., 2004; Drew and Pammenter, 2006). Extensive literature on genetic factors affecting the growth of trees can be found in the work of Kozlowski and Pallardy (1997). The most recent work by Downes et al. (2009) provides an excellent overview on measuring stem growth and wood formation. Other examples are those by Drew et al. (2009), which focussed on differences in daily stem diameter variation and growth in 
two hybrid eucalypts, and Zweifel et al. (2006) who studied the intra-annual radial growth and water relations of trees and the implications on growth mechanisms.

In a study that considered the data extracted from the same database as used in this study, Drew et al. (2009) found that the Eucalyptus grandis $\times$ Eucalyptus urophylla (GU) clone had fewer days on which net growth occurred than did the E. grandis $\times$ Eucalyptus camaldulensis (GC) clone. However, when growth did occur, the GU grew for longer each day and at a higher rate than did the GC. Thus, it still had an overall larger net stem increment during the study period. Drew et al. (2009) studied the relationship between stem radius and climatic factors using the correlation matrix.

Weather variables such as temperature, radiation, rainfall, humidity, and wind speed all contribute to the growth of the tree. For instance, Downes et al. (1999) studied daily radial stem growth in irrigated Eucalyptus globulus and Eucalyptus nitens in relation to climate over a 12-month period using multiple linear regression models. The study, which was conducted in southern Australia, showed that daily weather variation accounted for 40 to $50 \%$ of the variance in the daily increment of stem radius. Downes et al. (1999) also argued that understanding the relationship between weather and the rate and pattern of stem growth will facilitate the prediction of wood properties at a given site. Our approach provides an alternative one to the methods used by Downes et al. (1999). A study by Phipps (1982) presented a general discussion regarding problems inherent to developing climatically sensitive tree-ring chronologies from eastern North America. The same study by Phipps (1982) indicated that tree ring collections from eastern forests are typically not climatically sensitive as western collections. A general treatment of dendroclimatology can be found in the work of Fritts (1976). Other studies such as those by D'Arrigo et al. (1992), Hofgaard et al. (1999) and Schweingruber et al. (1993) reported that late spring or summer temperatures had a positive effect on annual growth. Zweifel et al. (2001) showed that radius change could be determined by stem water content and wood bark growth, including the degradation of dead phloem cells. The water related fraction is a short-term effect lasting from a few hours to several weeks, and can either have positive or negative effects on stem radius, depending on the changing turgor of stem tissues (Zweifel et al., 2001).

The contribution of each climatic variable is often influenced, by correlation, with one or more other climatic variables. However, studies that consider the effects of colinearity into account are limited. Studies commonly use diameter at a given tree age as an indicator of growth rate and pattern. Most eucalypt plantations are limited by rainwater for growth, therefore identification of the relationship between natural climatic conditions and radial increment is important for eucalypt plantation managers. In order to manage resources effectively, it is important for tree growers to understand the properties of the material being produced. This paper describes the effects of climatic variation on radial growth of $\mathrm{GU}$ and GC hybrid clones established in Zululand on the eastern coast of South Africa. The focus of this study is to determine the climatic factors that influence radial growth during the juvenile (the first 2 years of age) stages of tree growth. This is mainly because these data are the data collected on phase one of the data collection process. Moreover, the study of juvenile trees is very important, to have a productive matured tree. The primary question addressed by this study concerns the extent to which classical regression approaches are successful in detecting and estimating the effects of climatic conditions on stem radial growth. A secondary aim is to present latent variable modeling approaches, namely partial least squares (PLS) and principal component regression, for better estimation and detection of effects of the climatic variables.

\section{MATERIALS AND METHODS}

\section{Study design}

The research site is located near the town of KwaMbonambi in KwaZulu-Natal, South Africa, (28.53 ${ }^{\circ} \mathrm{S}, 32.14^{\circ} \mathrm{E}, 55 \mathrm{M}$ a.m.s.I), approximately $200 \mathrm{~km}$ north-east of the city of Durban. On average, the site receives $1,000 \mathrm{~mm}$ of rainfall per annum and has a mean annual temperature of $21^{\circ} \mathrm{C}$ (Drew et al., 2009). The Eucalyptus fiber research experiment was initiated in July, 2001 and a huge database acquired. The experiment was designed to run over a 7 year period and was divided into separate phases. Each phase ended with the destructive sampling of study trees to measure anatomical characteristics of the wood. The results presented in this paper are based on the data collected during the first of these phases, from April, 2002 until August, 2003. The data were used by Drew et al. (2009) and this particular study is extracted from the same database put in place by Sappi (One of the leading suppliers of coated fine paper and chemical cellulose). However, the two data sets are not exactly the same. Two commercially deployed Eucalyptus hybrid clones, GU and GC, were planted at the study site (Drew, 2004). According to the South African soil classification system, the soil was identified as Rhodic Ferralsol Hutton by a limited soil survey undertaken at the site (Soil classification workshop group, 1991). The soil is medium grade sand with clay percent in the lower B-horizon not exceeding $40 \%$, and in A-horizon not exceeding $10 \%$ with an average depth of A-horizon $20 \mathrm{~cm}$ and total potential rooting depth in excess of $1.8 \mathrm{~m}$ (Drew et al., 2009). Planting took place on 16 July, 2001, prior to which in April, 2001, stumps of trees from the previous rotation were treated with herbicide (to prevent coppicing), and harvest slash was burned. Each rooted cutting was planted between existing stumps, with approximately $2 \mathrm{~L}$ of water and $125 \mathrm{~g}$ granular fertilizer, the equivalent of $8 \mathrm{~g}$ nitrogen, $12 \mathrm{~g}$ phosphorus and $8 \mathrm{~g}$ potassium per plant. The two clones were planted in alternating rows seven trees wide each (Figure 1), with spacing between trees of $3 \mathrm{~m}$ (east to west) $\times 2.5 \mathrm{~m}$ (north to south). These rows have been numbered from 1 to 6 , starting at row (GC) closest to the entrance gate. Each row of clones consists of three plots of 12 trees each with two surrounding rows of trees (Figure 1). This effectively separates each plot by four rows of trees, an important part of the design since periodic destructive sampling is required in the experiment. The plots were established as pairs, such that for any phase of the 


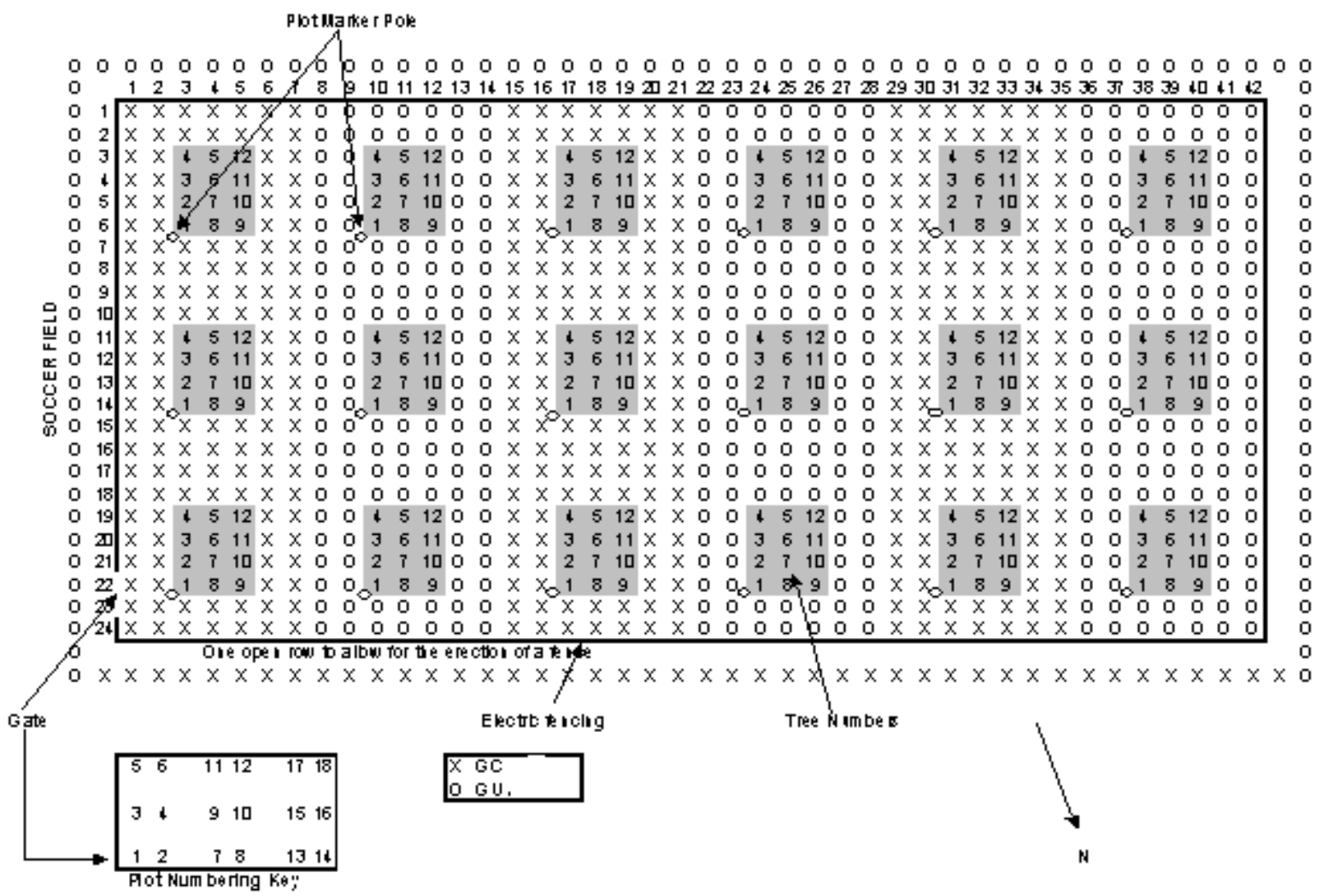

Figure 1. The layout of the experimental plots at the research site in eastern South Africa.

research, a GU and a GC plot could be measured simultaneously (Drew, 2004). From the 18 plots (Figure 1), plots 9 and 10 were chosen for monitoring during project Phase 1. Within a 12-tree plot, nine trees were selected from each clone for intensive monitoring of radial growth and other physiological characteristics (Drew, 2004). Measurements of stem radius were obtained from hourly dendrometer readings in the 18 sample trees. Automatic point dendrometers were mounted at 9 months of age at $1.3 \mathrm{~m}$ above the ground on the north side of each tree to measure the radius of the main stem with a rod held against the outside surface by constant force. The data for stem radius used in this paper has 8640 observations from the two clones. Half the data set is from the GU clone and the remaining half is from the GC clone. Daily measurements were used in our analysis. Daily averages of stem radius were obtained by cumulating and averaging the hourly measurements. Meteorological data was obtained using an automatic weather station (MCSystems, Cape Town, South Africa) located approximately $300 \mathrm{~m}$ from the research trial site (Drew et al., 2009). Hourly measurements were made of total rainfall $(\mathrm{mm})$, temperature $\left({ }^{\circ} \mathrm{C}\right)$, relative humidity $(\%)$, wind speed $(\mathrm{m} / \mathrm{s})$ and total solar radiation $(\mathrm{mJ} / \mathrm{h})$. Daily total rainfall and daily averages of the other weather variables were used in the analysis.

\section{Data analysis}

Statistical analysis was undertaken using R-statistical software. $R$ is a free software that can be downloaded from the R-project website $\mathrm{R}$ Core Team (2012). The simplest approach in detecting climatic effects is by the use of traditional regression methods. However, this traditional method assumes that the climatic variables are uncorrelated since one of the failures of regression methods is due to multicollinearity. Multicollinearity problem arises when the predictors (in our case the climatic variables) are correlated. To overcome this, we applied principal component regression and PLS regression. These methods were applied to the combined data set as well as to the data set for separate clones. Extensive discussion of these methods can also be found in Rodriguez-Nogales (2006), Dine et al. (2002), Fekedulegn et al. (2002), Maitra and Yan (2008), Mevik and Cederkvist (2004), and Haenlein and Kaplan (2004).

\section{RESULTS AND DISCUSSION}

The variables included in the study are major climatic variables and one non-climatic variable (tree age) as previously described. The overall ordinary least squares (OLS) model was significant with an $R^{2}=0.791$ and adjusted $R^{2}=0.79$ (Table 1 ). This indicates that about $79 \%$ of the variation in stem radius is explained by the predictors (the five weather variables together with age of a tree) included in the model. An attempt to explore lags was made by considering lags up to 15 days. The use of five weather variables lagged by 15 days increased the variance explained by $0.3 \%$ only. Therefore, we did not consider the lags as an important issue at this age of the tree.

The predictors included in the model are therefore important for determining radial tree growth. However, 
Table 1. Summary OLS model.

\begin{tabular}{lcccc}
\hline Predictor (climatic variables) & Estimate & Standard error & t-value & p-value \\
\hline Intercept & -16558.67 & 550.61 & -30.07 & 0.000 \\
Temperature & 23.73 & 12.65 & 1.88 & 0.061 \\
Solar radiation & 2865.35 & 222.01 & 12.91 & 0.000 \\
Rainfall & 2.57 & 6.21 & 0.41 & 0.679 \\
Wind speed & 1426.83 & 77.02 & 18.53 & 0.000 \\
Tree age & 313.22 & 2.21 & 142.05 & 0.000 \\
$\mathrm{R}^{2}=0.791$ & & $\mathrm{Adj}^{2}=0.79$ & & \\
\hline
\end{tabular}

Table 2. Correlation matrix of predictors.

\begin{tabular}{lcccc}
\hline Variable & Temperature & Relative humidity & Solar radiation & Rainfall \\
\hline Temperature & 1 & & & \\
Relative humidity & $-0.320^{* *}$ & 1 & & \\
Solar radiation & $0.617^{* *}$ & $-0.498^{* *}$ & 1 & \\
Rainfall & $-0.107^{* *}$ & $0.272^{* *}$ & $-0.258^{* *}$ & 1 \\
Wind speed & $0.406^{* *}$ & $-0.385^{* *}$ & $0.374^{* *}$ & $0.099^{* *}$ \\
\hline
\end{tabular}

${ }^{*}$ Correlation is significant at the 0.05 level (2-tailed). ${ }^{*}$ Correlation is significant at the 0.01 level (2tailed).

Table 3. The eigen value decomposition of the correlation matrix.

\begin{tabular}{ccc}
\hline Eigen values & Proportion of total & Cumulative proportion of total \\
\hline 2.375 & 0.396 & 0.396 \\
1.252 & 0.209 & 0.605 \\
1.083 & 0.181 & 0.786 \\
0.625 & 0.104 & 0.890 \\
0.412 & 0.069 & 0.959 \\
0.253 & 0.042 & 1 \\
\hline
\end{tabular}

the individual t-ratios (estimated coefficient/standard error) for the coefficients of the most important climatic variables, that of rainfall and temperature, are nonsignificant (Table 1). This is an indication of the presence of multicollinearity among the predictors. From the correlation matrix of predictors (Table 2), temperature and solar radiation were highly correlated. The correlation coefficient was 0.62 and highly significant $(p<0.001)$. The correlation between wind speed and temperature was 0.41 , which was also highly significant $(p<0.001)$. This shows the existence of significant multicollinearity among the independent climatic variables. Multicollinearity inflates the standard error of the regression coefficients, which results in low t-statistic values and a failure to reject the null hypothesis. The application of classical linear regression models therefore does not have a powerful inference on the regression coefficients. To address this problem, principal component regression and
PLS regression techniques were used. All predictors were treated as continuous variables with different unit of measurements [for instance, rainfall $(\mathrm{mm})$ and temperature $\left({ }^{\circ} \mathrm{C}\right)$ ]. It might make more sense to standardize the predictors before trying principal components. This is equivalent to performing principal components analysis on the correlation matrix of predictor variables. Table 3 shows the eigen value decomposition of the correlation matrix of the original or the covariance matrix of the standardized predictors. The first five principal components captured $95.9 \%$ of the information in the correlation matrix. Table 4 shows the eigen vectors corresponding to each of the eigen values of Table 3 . We constructed the principal components corresponding to each eigen value by linearly combining the standardized predictive variables using the corresponding eigen vector. Hence, the six principal components are computed as follows: 
Table 4. The eigen vectors associated with the eigen values of Table 3.

\begin{tabular}{cccccc}
\hline Eigen vector $\mathbf{1}$ & Eigen vector $\mathbf{2}$ & Eigen vector 3 & Eigen vector 4 & Eigen vector $\mathbf{5}$ & Eigen vector $\mathbf{6}$ \\
\hline 0.495 & -0.239 & -0.031 & 0.601 & -0.463 & 0.347 \\
-0.488 & -0.415 & 0.085 & 0.301 & -0.362 & -0.593 \\
0.546 & -0.144 & 0.168 & 0.238 & 0.553 & -0.539 \\
-0.207 & -0.255 & -0.808 & 0.259 & 0.396 & 0.127 \\
0.413 & -0.280 & -0.431 & -0.594 & -0.366 & -0.279 \\
-0.068 & -0.774 & 0.354 & -0.266 & 0.241 & 0.378 \\
\hline
\end{tabular}

Table 5. Summary of OLS model that uses principal components as predictors.

\begin{tabular}{lcccc}
\hline Coefficient & Estimates & Standard error & t-value & p-value \\
\hline Intercept & 16025.71 & 36.70 & 439.659 & $<2 \mathrm{e}-16^{* * *}$ \\
$\mathrm{PC}_{1}$ & 60.83 & 23.82 & -2.554 & $0.0107^{*}$ \\
$\mathrm{PC}_{2}$ & -5402.82 & 32.80 & -164.713 & $<2 \mathrm{e}-16^{* * *}$ \\
$\mathrm{PC}_{3}$ & 1987.07 & 35.27 & 56.34 & $<2 \mathrm{e}-16^{* * *}$ \\
$\mathrm{PC}_{4}$ & -1742.90 & 46.42 & -35.547 & $<2 \mathrm{e}-16^{\text {***}}$ \\
$\mathrm{PC}_{5}$ & 1330.27 & 57.18 & -23.263 & $<2 \mathrm{e}-16^{\text {***}}$ \\
$\mathrm{PC}_{6}$ & 1425.38 & 72.99 & 19.530 & $<2 \mathrm{e}-16^{\text {***}}$ \\
\hline
\end{tabular}

*Significance at the 0.05 level. ${ }^{* * *}$ significance at the 0.001 level.

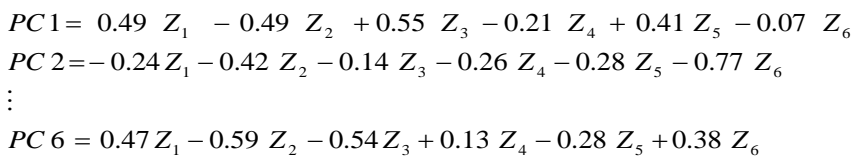

where $Z_{1}$ is the standardized value of temperature, $Z_{2}$ is the standardized value of relative humidity, $Z_{3}$ is the standardized value of solar radiation, $Z_{4}$ is the standardized value of rainfall, $Z_{5}$ is the standardized value of wind speed, and $Z_{6}$ is the standardized value of age

The principal components constructed above were used in a linear regression model. Stem radius was used as the dependent variable and the principal components as independent variables (Table 5). The rank of the predictive power did not line up with the order of the principal components. For instance, the first principal component was less explanatory for the target than the second or the third, even though the first principal component contains more information on the six original explanatory variables. The principal components technique arrives at uncorrelated standardized linear combinations (SLCs) that capture only the characteristics of the Xvector or predictive variables. No significance is given as to how each predictive variable is related to the response variable. In a way, it is an unsupervised dimension reduction technique (Maitra and Yan, 2008) and therefore requires the use of other analytical methods such as PLS.

In comparing the importance of the constructed principal components, five components explained most of the variation in the predictors (95.9\%). The scree plot (not shown here) showed that almost all the variation in predictors (about 96\%) was explained by the first five principal components. Therefore, a linear model that used the first five principal components as latent explanatory variables was fitted (Table 6 ). The $R^{2}$ value 0.78 for the reduced model was close to the $R^{2}$ value for the model with all six components $\left(R^{2}=0.79\right)$. Once again, the rank of the predictive power did not correspond with the order of the principal components. In other words, principal component one appears to have less explanatory power for the dependent variable as compared to other components. By transforming the principal components back to the original explanatory variables, the estimated coefficients of the original variables are given in Table 7. That means, firstly, the principal components were obtained. These principal components are uncorrelated and an ordinary regression model was fitted using the principal components as explanatory variables. The five principal components appear to have significant effect on the radial measure (Table 6). The estimated coefficients for the original measured variables were obtained by transformation from the estimated coefficients for principal components. The estimates of the regression coefficients in Table 7 show that all predictors have a positive relationship with stem radial measure. Moreover, the five latent variables that produced the above estimated coefficients are significant (Table 6). This indicates the significant effect of climatic variables on radial measure. Separate estimates for GU and GC clones also show the positive 
Table 6. Summary of OLS results for the model that uses the first five principal components.

\begin{tabular}{ccccc}
\hline Coefficient & Estimates & Standard error & t-value & p-value \\
\hline Intercept & 16025.71 & 37.50 & 427.35 & $<2 \mathrm{e}-16^{\star \star *}$ \\
$\mathrm{PC}_{1}$ & 60.83 & 24.34 & -2.50 & $0.0124^{*}$ \\
$\mathrm{PC}_{2}$ & -5402.82 & 33.52 & -161.20 & $<2 \mathrm{e}-16^{\star \star *}$ \\
$\mathrm{PC}_{3}$ & 1987.07 & 36.04 & 55.14 & $<2 \mathrm{e}-16^{\star \star \star}$ \\
$\mathrm{PC}_{4}$ & -1742.90 & 47.43 & -36.75 & $<2 \mathrm{e}-16^{\star \star *}$ \\
$\mathrm{PC}_{5}$ & 1330.27 & 58.43 & -22.77 & $<2 \mathrm{e}-16^{\star \star \star}$ \\
\hline
\end{tabular}

*Significance at the 0.05 level. ${ }^{* *}$ Shows significance at the 0.001 level.

Table 7. The estimated coefficients of the original climatic variables estimated by using principal component regression.

\begin{tabular}{lccc}
\hline Predictors (Climatic variables) & Estimates for combined data & Estimates for GU clone & Estimates for GC clone \\
\hline Intercept & -16558.67 & -19048.26 & -14069.07 \\
Temperature & 90.48 & 165.33 & 15.64 \\
Relative humidity & 581.14 & 680.05 & 482.29 \\
Solar radiation & 694.56 & 802.99 & 586.20 \\
Rainfall & 16.81 & 27.82 & 5.79 \\
Wind speed & 834.13 & 902.12 & 766.24 \\
Tree age & 6201.39 & 6764.65 & 5638.85 \\
\hline
\end{tabular}

Table 8. Estimated coefficients of the original set of climatic variables using PLS method.

\begin{tabular}{lccc}
\hline Climatic variable & Estimates for both clones & Estimates for GU clone & Estimates for GC clone \\
\hline Temperature & 55.42 & 128.02 & 54.42 \\
Relative humidity & 596.58 & 696.94 & 596.58 \\
Solar radiation & 761.13 & 874.50 & 761.13 \\
Rainfall & 35.13 & 47.59 & 35.13 \\
Wind speed & 814.29 & 880.65 & 814.29 \\
Tree age & 6191.69 & 6754 & 6191.69 \\
\hline
\end{tabular}

effect of weather variables together with tree age (Table 7). Partial least square regression (PLS) can overcome the deficiencies of OLS regression in the case of highly collinear data. Moreover, partial least squares allow an analysis of the data in terms of independent latent variables or components. Applying PLS method to the data, the minimum root mean square error of prediction (RMSEP) is observed for five components model. The value of the $X$-variance for the model with five latent variables is $93.5 \%$. This means a model with five latent variables has explained $93.5 \%$ of the variation in the original predictors. The variation explained in the response variable is $79.1 \%$. This is the same amount of variation explained by the ordinary least square regression. Therefore, the model formulated by five latent variables fits the data well with a high predictive power. The coefficients for the original set of variables when partial least square regression was applied to GC, GU and pooled data sets are indicated in Table 8. It appears that the estimated coefficients for the original set of variables for the GC clone are smaller than that of the GU clone for all climatic variables. This indicates that the GU clone has on average a larger stem radius than the GC clone. The signs of the estimated coefficients for the GU clone and the signs for the estimated coefficients of the pooled data set are the same. However, the estimated coefficient of temperature is negative for the GC clone while it is positive for the GU clone and pooled data set. This indicates that the effect of temperature on stem radius goes in opposite directions for the two clones for this site and age class. The possible reason for this could be the difference in genetic makeup the two clones. Moreover, the effect of weather variables may depend on the season of the year. The site difference cannot be a possible reason for this difference as site difference is controlled by the design. In the design the plots were established as pairs such that a GU and a GC plots are measured simultaneously (Figure 1). For the rest of the climatic variables the effect follows the same direction for the two clones with some differences in magnitude.

In order to test whether the components that produced these coefficients are significant or not, latent variables or 
Table 9. Summary of OLS results for the model that uses the PLS components as predictors.

\begin{tabular}{lcccc}
\hline Coefficient & Estimates & Standard error & t-value & p-value \\
\hline Intercept & 16025.71 & 36.70 & 436.64 & $<2 \mathrm{e}-16^{\star \star \star}$ \\
$\mathrm{T}_{1}$ & 5932.81 & 32.29 & 178.23 & $<2 \mathrm{e}-16^{\star \star \star}$ \\
$\mathrm{T}_{2}$ & 1193.6 & 45.41 & 26.28 & $<2 \mathrm{e}-16^{\star \star \star}$ \\
$\mathrm{T}_{3}$ & 318.38 & 30.45 & 10.46 & $<2 \mathrm{e}-16^{\star \star \star}$ \\
$\mathrm{T}_{4}$ & 299.85 & 40.22 & 7.46 & $9.83 \mathrm{e}-14^{\star \star \star}$ \\
$\mathrm{T}_{5}$ & 212.74 & 48.99 & 4.34 & $1.42 \mathrm{e}-05^{\star \star \star}$ \\
$\mathrm{T}_{6}$ & 78.66 & 58.87 & 1.336 & 0.182 \\
\hline
\end{tabular}

${ }^{* *}$ Significance at the 0.001 level.

Table 10. Summary of OLS results for the model that uses the first five PLS components as predictors.

\begin{tabular}{lcccc}
\hline Coefficient & Estimates & Standard error & t-value & p-value \\
\hline Intercept & 16025.71 & 36.70 & 436.64 & $<2 \mathrm{e}-16^{\star \star *}$ \\
$\mathrm{~T}_{1}$ & 5932.81 & 32.29 & 178.23 & $<2 \mathrm{e}-16^{\star * *}$ \\
$\mathrm{~T}_{2}$ & 1193.6 & 45.41 & 26.28 & $<2 \mathrm{e}-16^{\star \star *}$ \\
$\mathrm{~T}_{3}$ & 318.38 & 30.45 & 10.46 & $<2 \mathrm{e}-16^{\star * \star}$ \\
$\mathrm{T}_{4}$ & 299.85 & 40.22 & 7.46 & $9.83 \mathrm{e}-14^{\star \star *}$ \\
$\mathrm{~T}_{5}$ & 212.74 & 48.99 & 4.34 & $1.42 \mathrm{e}-05^{\star \star *}$ \\
\hline
\end{tabular}

${ }^{* * *}$ Significance at the 0.001 level.

Table 11. RMSE and RMSECV values for all prediction methods.

\begin{tabular}{lccc}
\hline Parameter & OLS & PCR & PLS \\
\hline RMSE & 3410.01 & 3484.53 & 3410.4 \\
RMSECV & 3414.39 & 3413 & 3413 \\
\hline
\end{tabular}

PLS components were constructed while fitting the PLS regression. After determining these latent variables, $T_{1} \ldots T_{6}$ sequentially, the relationship between these latent constructs and the response was estimated by ordinary linear regression. The sample correlations between any pair of the latent constructs were zero. A linear model was then applied using the same radial measure as the dependent variable and the six PLS components, $T_{1} \ldots T_{6}$, as the independent variables. Summary results for the model that uses the PLS components as predictors is shown in Table 9. The PLS components were extracted in order of significance. The first five components were significant, while the last component was not. The values of $R^{2}$ and adjusted $R^{2}$ for this model were 0.7908 and 0.7907 , respectively. Table 10 shows the summary results for the model that involves only five PLS components. From the results, it can be seen that all the coefficients listed in Tables 9 and 10 were the same for the first five components. This shows that the coefficients of the PLS latent variables do not change by adding or dropping latent variables from the model. The results of the PLS model show that all climatic variables had a significant effect on growth.

With regard to the predictive powers of these models, a comparison was made based on RMSE and the RMSE of cross-validation (RMSECV, Table 11), a measure of the model's ability to predict new samples. The OLS model had the smallest RMSE value (Table 11). The second smallest RMSE values belong to the PLS model.

The RMSE for PLS was actually very close to the RMSE for the OLS model. However, this comparison was from the point of view of model fit. Under the condition of no multicollinearity, this might indicate that the OLS model fitted the data better than the other two methods. For comparisons of models intended for prediction, it is inadequate to look just at model fit. As prediction is the objective, the PLS model that gave the lowest RMSECV value is preferred. For the data set to which these models were applied, the PLS model had the highest predictive ability with the lowest number of factors. In order to identify differences between clones, separate PLS model was fitted to data for each clone. For both clones, the optimum number of PLS components was five. These five components were significant, while the sixth 
Table 12. Percent of variance captured by PLS components for GU clone.

\begin{tabular}{lcccc}
\hline \multirow{2}{*}{ Component } & \multicolumn{2}{c}{ Climatic variables and age } & \multicolumn{2}{c}{ Radius } \\
\cline { 2 - 5 } & This component & Cumulative total & This component & Cumulative total \\
\hline $\mathrm{T}_{1}$ & 20.53 & 20.53 & 77.53 & 77.53 \\
$\mathrm{~T}_{2}$ & 17.66 & 38.19 & 1.86 & 79.04 \\
$\mathrm{~T}_{3}$ & 30.25 & 68.44 & 0.35 & 79.39 \\
$\mathrm{~T}_{4}$ & 15.27 & 83.71 & 0.14 & 79.53 \\
$\mathrm{~T}_{5}$ & 9.8 & 93.51 & 0.04 & 79.57 \\
\hline
\end{tabular}

Table 13. Percent of variance captured by PLS components for GC clone.

\begin{tabular}{lcccc}
\hline \multirow{2}{*}{ Component } & \multicolumn{2}{c}{ Climatic variables and age } & \multicolumn{2}{c}{ Radius } \\
\cline { 2 - 5 } & This component & Cumulative total & This component & Cumulative total \\
\hline $\mathrm{T}_{1}$ & 20.47 & 20.47 & 84.74 & 84.74 \\
$\mathrm{~T}_{2}$ & 12.25 & 32.72 & 2.06 & 86.80 \\
$\mathrm{~T}_{3}$ & 25.85 & 58.57 & 0.25 & 87.05 \\
$\mathrm{~T}_{4}$ & 24.28 & 82.85 & 0.11 & 87.16 \\
$\mathrm{~T}_{5}$ & 10.68 & 93.53 & 0.05 & 87.21 \\
\hline
\end{tabular}

Table 14. Standardized regression weights for both principal component regression and PLS regression models.

\begin{tabular}{lcccc}
\hline Predictor & \multicolumn{2}{c}{ PLS model } & \multicolumn{2}{c}{ PCR model } \\
\cline { 2 - 5 } (climatic variables) & GU & GC & GU & GC \\
\hline Temperature & 0.016 & -0.003 & 0.020 & 0.002 \\
Relative humidity & 0.086 & 0.078 & 0.083 & 0.075 \\
Solar radiation & 0.107 & 0.101 & 0.098 & 0.091 \\
Rainfall & 0.006 & 0.004 & 0.003 & 0.001 \\
Wind speed & 0.108 & 0.116 & 0.110 & 0.119 \\
Tree age & 0.829 & 0.876 & 0.830 & 0.878 \\
\hline
\end{tabular}

component was not significant (Table 9). The percentage of total variation in radial measure captured by the number of components for the GU clone is less (Table 12: $80 \%$ with $p$-value $<0.0001)$ than the amount of variation captured for the GC clone (Table 13: $87.21 \%$ with $p$-value $<0.0001)$. The percentage of total variation in climatic variables and tree age captured by the five components PLS model for the GU and GC clones is almost the same (93.5\%).

In order to determine the most important drivers of variation in short-term stem radial measure (for the first 2 years of tree age) for the two clones, we applied standardized regression weights for both PLS and principal component regressions. This can be obtained by fitting the models on standardized variables. The factor with the highest coefficient in absolute value is the most important factor in explaining the variation in radial measure. The standardized regression weights (coefficients) for our predictors, when PLS regression and principal components regression were applied to GC and
GU data sets, are indicated in Table 14. It appears that tree age is the most important predictor of stem radius using both models and for both clones. Among climatic variables, it appears that wind speed, followed by solar radiation, is the most important driver of the variation in stem radius over the growth period of 2 years. However, the biological plausibility of these results is questionable. Moreover, we found the negative effect of temperature for GC clone. This might be due to the dependence of weather variables on season. The weather variables are likely to change over the year. This relative effect of weather variable might change from one season to the other. We analyzed the same data by season in order to see for the season effect. Summary results by season are shown in Tables 15 and 16. In spring and summer, none of the weather variables has significant effect. The only variable that has significant effect on stem radius is tree age. In winter, all predictors have significant effect on stem radius for GU clone, while for GC clone all have significant effect with the exception of rainfall. In autumn, 
Table 15. Summary results of ordinary regression model for summer and autumn.

\begin{tabular}{|c|c|c|c|c|}
\hline \multirow{3}{*}{ Predictor } & \multicolumn{4}{|c|}{ Summer } \\
\hline & \multicolumn{2}{|c|}{ GC clone } & \multicolumn{2}{|c|}{ GU clone } \\
\hline & Estimate & $p$-value & Estimate & p-value \\
\hline Intercept & 2763.099 & 0.265 & 2695.785 & 0.588 \\
\hline Temperature & -2.143 & 0.963 & -17.097 & 0.854 \\
\hline Relative humidity & 5.088 & 0.781 & 9.983 & 0.786 \\
\hline Solar radiation & 167.126 & 0.712 & 371.769 & 0.683 \\
\hline Rainfall & 0.291 & 0.990 & 0.422 & 0.993 \\
\hline Wind speed & -47.827 & 0.813 & -80.071 & 0.844 \\
\hline \multirow[t]{2}{*}{ Tree age } & 185.506 & 0.000 & 231.252 & 0.000 \\
\hline & \multicolumn{2}{|c|}{$R^{2}=0.107$} & \multicolumn{2}{|c|}{$R^{2}=0.045$} \\
\hline & \multicolumn{4}{|c|}{ Autumn } \\
\hline \multirow{2}{*}{ Predictor } & \multicolumn{2}{|c|}{ GC clone } & \multicolumn{2}{|c|}{ GU clone } \\
\hline & Estimate & P-value & Estimate & P-value \\
\hline Intercept & -11156.222 & 0.000 & 15921.22 & 0.000 \\
\hline Temperature & -12.152 & 0.578 & 28.38 & 0.377 \\
\hline Relative humidity & 8.632 & 0.441 & 19.62 & 0.233 \\
\hline Solar radiation & 1055.849 & 0.028 & 1907.87 & 0.007 \\
\hline Rainfall & 13.029 & 0.550 & 23.89 & 0.029 \\
\hline Wind speed & 378.068 & 0.011 & 476.58 & 0.029 \\
\hline \multirow[t]{2}{*}{ Tree age } & 316.093 & 0.000 & 382.49 & 0.000 \\
\hline & \multicolumn{2}{|c|}{$R^{2}=0.929$} & \multicolumn{2}{|c|}{$R^{2}=0.9$} \\
\hline
\end{tabular}

Table 16. Summary results of ordinary regression model for winter and spring.

\begin{tabular}{|c|c|c|c|c|}
\hline \multirow{3}{*}{ Predictor } & \multicolumn{4}{|c|}{ Winter } \\
\hline & \multicolumn{2}{|c|}{ GC clone } & \multicolumn{2}{|c|}{ GU clone } \\
\hline & Estimate & $p$-value & Estimate & p-value \\
\hline Intercept & -12364.279 & 0.000 & -14159 & 0.000 \\
\hline Temperature & 137.832 & 0.000 & 159.339 & 0.000 \\
\hline Relative humidity & 39.106 & 0.000 & 46.699 & 0.000 \\
\hline Solar radiation & 1980.674 & 0.000 & 1775.888 & 0.021 \\
\hline Rainfall & -5.541 & 0.442 & -7.936 & 0.046 \\
\hline Wind speed & 659.705 & 0.000 & 698.642 & 0.002 \\
\hline \multirow{2}{*}{ Tree age } & 266.982 & 0.000 & 312.839 & 0.000 \\
\hline & \multicolumn{2}{|c|}{$R^{2}=0.896$} & \multicolumn{2}{|c|}{$R^{2}=0.841$} \\
\hline & \multicolumn{4}{|c|}{ Spring } \\
\hline \multirow[t]{2}{*}{ Predictor } & \multicolumn{2}{|c|}{ GC clone } & \multicolumn{2}{|c|}{ GU clone } \\
\hline & Estimate & P-value & Estimate & P-value \\
\hline Intercept & -2217.472 & 0.077 & -8561.296 & 0.002 \\
\hline Temperature & -20.944 & 0.366 & -40.28 & 0.434 \\
\hline Relative humidity & -0.688 & 0.941 & -2.816 & 0.893 \\
\hline Solar radiation & 56.458 & 0.855 & 110.533 & 0.872 \\
\hline Rainfall & -1.488 & 0.870 & -1.53 & 0.939 \\
\hline Wind speed & 31.297 & 0.788 & 65.365 & 0.801 \\
\hline \multirow[t]{2}{*}{ Tree age } & 262.869 & 0.000 & 403.825 & 0.000 \\
\hline & \multicolumn{2}{|c|}{$R^{2}=0.282$} & \multicolumn{2}{|c|}{$R^{2}=0.158$} \\
\hline
\end{tabular}

solar radiation, wind speed and tree age have significant effects on the stem radius for both clones. In autumn, rainfall appears to have significant effect on stem radius for GU clone, while it has no significant effect on GC 
clone. The insignificant effect rainfall in winter and autumn for GC clone might be due to genetic factor, which needs further study. Temperature has significant effect and positively related to stem radius in winter for both clones (Table 16). In summer, autumn and spring, temperature has no significant effect on stem radius (Tables 15 and 16). Therefore, the effect of weather variables on stem radius is dependent on season.

Daily stem size variation is important as the net increment of a forest stand is ultimately determined by the accumulation of daily increment events (Drew et al., 2009). Several factors might affect the daily stem size of trees. For instance, the study by Zweifel et al. (2006) indicates that there is a strong dependence of radial growth on the current tree-water relations and only secondary dependence on the carbon-balance. The availability of soil water and the degree to which storage tissues were saturated were also factors affecting the diurnal course of stem radius changes (Zweifel et al., 2001). Whitehead and Jarvis (1981) have suggested in theoretical approaches, that the diurnal stem radius fluctuations are coupled to tree-water relations by changing water potential gradients within the tree. Studies by Downs et al. (1999) and Deslauriers et al. (2003) consider the effect of weather on daily stem growth. Deslauriers et al. (2003) studied daily stem radial growth of balsam fir to show that total rainfall and maximum temperature were positively correlated with the stem radius. Climatic variables are highly inter-correlated, and the use of OLS to estimate the parameters of the response function results in instability and high variability of the regression coefficients. As a result, the regression coefficients become much larger than would seem reasonable physically or practically, and may fluctuate widely in sign and magnitude. Accordingly, it was observed that the ordinary regression estimates inflated the percentage of variation in the stem radial growth accounted for by climatic conditions. Ordinary regression inferences from such correlated climatic variables can result in misleading and confusing conclusions relating to variables of major interest to dendroecologists in terms of magnitude, sign, and standard error of the coefficients as well as $R^{2}$ (Fekedulegn et al., 2002).

Both principal component regression and PLS regression methods have an advantage over OLS regression because they do not require that the explanatory variables be orthogonal. The principal components are orthogonal, eliminating the multicollinearity problem. However, the problem of choosing an optimum subset of predictors remains. A possible strategy is to keep only a few of the first components. Nevertheless, the components are chosen to explain the independent $(X)$ rather than the dependent $(Y)$ and there are no guarantees that the principal components which explain the independent variable can be relevant to explain the dependent $(Y)$. On the other hand, PLS regression finds components from $X$ that are also relevant for $Y$. PLS regression searches for a set of components that perform a simultaneous decomposition of $\mathrm{X}$ and $\mathrm{Y}$ with the constraint that these components explain much of the covariance between $X$ and $Y$. The PLS approach is considered as a variance-based structural equation model (SEM). The alternative SEM is a covariance-based SEM. Although both methods use a latent variable term, the latent variables used by the two methods are different. As indicated by Fornell and Bookstein (1982), the latent variables in PLS are estimated as exact linear combinations of their indicators. This shows that "latent" variables in PLS are not true latent variables as defined in SEM, as they are not derived to explain the covariation of their indicators, but only to approximate them (Mathes, 1993; McDonald, 1996). On the other hand, the latent variables in covariance-based SEMs are true latent variables. That is they are hypothetically existing entities or constructs. In other words, the covariance-based SEM latent variables cannot be found as weighted sums of manifest variables; they can only be estimated by such weighted sums (Schneewiss, 1993). Arguably, PLS has the advantage over the covariance based SEM, in that Jöreskog and Wold (1982) and Wold (1982, 1985) referred to PLS technique as "soft modeling", because it did not require the "hard" distributional assumptions of maximum likelihood (ML) which is the core technique in SEM, and because it uses a suboptimal estimation technique that is faster to run than ML-SEM, which therefore allows for more user interaction.

Finally, the latent variable model approaches used in our study show that all climatic variables measured and tree age are positively correlated with stem radial measure for the pooled data of both clones. Moreover, all latent variables had significant effects on the radial measure. This was not the case when OLS was applied. The effects of the two most important variables, rainfall and temperature, were not significant when the OLS method was used (Table 1). This may be because the ordinary linear regression assumes that the predictors are uncorrelated, while in our case the climatic variables are correlated (Table 2). It may also be because the effect of weather variables changes with season. To overcome the problem of correlation among weather variables, two alternative methods (Principal component regression and PLS) were used. Principal component regression models were fitted for the GC and GU clones separately, resulting in a positive effect of climatic variables on stem radius for both clones. The weather data together with the age of a tree accounted for $79 \%$ of the variance in the stem radial growth for the combined data set. This is equivalent to $R^{2}$ in OLS regression. The separate analysis of GC and GU clones showed that the weather variables and tree age explained 87 and $79.6 \%$ of the total variation in radial measure for the GC and GU clones, respectively.

When comparing the PLS model fitted for the GC clone and GU clone, the effect of climatic variables is similar for the two clones except for the effect of temperature. Temperature appears to have an opposite effect on the 
radial growth of the two clones. Moreover, $87 \%$ of the total variation in the stem radial measure is explained by the weather variables and tree age by using the PLS method for the GC clone and $79 \%$ of the variation is explained for the GU clone. This indicates that the amount of explained variation is larger for the GC clone than for the GU clone. The evaluation of the relationship between weather variables and stem radius is considered after separating the data by season. The effect of weather variables on stem radius was found different for different seasons. Tree age is the most important factors that influences change in stem radius. The importance of tree age in determining stem radius should be expected as growth is positively related to age most of the time. There is no significant effect of weather variables on stem radius during summer and spring for both GU and GC clones. In autumn, there is significant effect of some variables (tree age, solar radiation, wind speed) for both GU and GC clones. In winter, the variables temperature, relative humidity, solar radiation, wind speed and tree age have significant positive relationship with stem radius for both clones (Table 16).

\section{Conclusions}

The study demonstrated that the relationships between the daily stem radius and weather variables is positive for both the GU and GC clones with the exception of temperature. This conclusion was drawn without considering season. The analysis by season shows that there is no relationship between weather variables (temperature, relative humidity, solar radiation, wind speed and rainfall) and stem radius for two seasons (summer and spring). In winter, there is a positive relationship between each of the variables (tree age, temperature, relative humidity, solar radiation and wind speed) and stem radius. In autumn, the relationship between stem radius and variables (solar radiation, wind speed and tree age) is positive for both clones. In autumn and winter, the effect rainfall on stem radius is significant for GU clone, while it is not significant for GC clone. This could be mainly due to genetic difference between the two clones. This may need further research in the area. The study also helps not only to see the role of climatic variables on the radial growth but also can be an example of an analysis of the effect of correlated predictors on the growth of plants in general. Regarding the statistical methods used in this study, PLS method appears to be best in solving the problem of multicollinearity. However, it is advisable to analyze the data using different alternative methods before we embark on conclusion. From this study, the lesson learnt is that the consideration of seasonal effect is indispensable, to study the effect of weather variables on tree growth.

In conclusion, the climatic variables, together with tree age, explained a substantial amount of variation $(79 \%)$ in the stem radius. Tree age is the most important factor that influences change in stem radius. The importance of weather variables depends on season. In autumn, solar radiation and wind speed appears to be more important than the other weather variables. In winter, temperature, relative humidity and wind speed are more important than other weather variables in determining stem radius. This study is based on data collected at the juvenile stage of Eucalyptus trees. The application of the same techniques to adult trees and comparison of the results shall be the subject of future work.

\section{ACKNOWLEDGEMENTS}

The authors are grateful to Dr Valerie Grzekowiak and Dr Nicky Jones for their valuable comments and suggestions.

\section{REFERENCES}

Callaham RZ. (1962). Geographic variability in growth of forest trees. In: Kozlowski T (ed.), Tree Growth. New York: The Ronald Press Company. pp. 311-325.

D'Arrigo RD, Jacoby GC, Free RM (1992). Tree-ring width and maximum latewood density at the North American tree line: parameters of climate change. Canadian J. Forest. Res. 22:1290 1296.

Deslauriers A, Morin H, Urbinati C, Carrer M (2003). Daily weather response of balsam fir [Abies balsamea (L.) Mill.] stem radius increment from dendrometer analysis in the boreal forests of Quebec (Canada). Trees (Berl) 17:477-484.

Dine E, Yücesoy C, Onur F (2002). Simultaneous spectrophotometric determination of mefenamic acid and paracetamol in a pharmaceutical preparation using ratio spectra derivative spectrophotometry and chemometric methods. J. Pharm. Biomed. Anal. 2:1091-1100.

Downes G, Beadle C, Worledge D (1999). Daily stem growth patterns in irrigated Eucalyptus globules and E.nitens in relation to climate. Trees 14:102-111.

Downes G, Drew D, Battaglia M, Schulze D (2009). Measuring and modeling stem growth and wood formation: an overview. Dendrochronologia 27:147-157.

Drew DM (2004). Dendrometer trial phase one technical report. Report No. EFR092T. Division of Water, Environment and Forestry Technology, CSIR.

Drew D, Downes G, Grzeskowiak V and Naidoo T (2009). Differences in daily stem size variation and growth in two hybrid eucalypt clones. Trees - Stru. Function. 23:585-595.

Drew DM, Pammenter NW (2006). Vessel frequency, size and arrangement in two eucalypt clones growing at sites differing in water availability. New Zealand J. Forest. 51:23-28.

February EC, Stock WD, Bond WJ, Le Roux DJ (1995). Relationships between water availability and selected vessel characteristics in Eucalyptus grandis and two hybrids. IAWA J. 16:269-276.

Fekedulegn BD, Colbert JJ, Hicks RR, Schucker ME (2002). Coping with multicolinerarity: an example on application of Principal Components Regression in Dendroecology. Research, Paper NE721. United States Department of Agriculture.

Fornell C, Bookstein F (1982). Two structural equation models: LISREL and PLS applied to Consumer Exit-Voice Theory. J. Mark. Res. 19:440-452.

Fritts HC (1976). Tree rings and climate. New York: Academic Press. pp. 28-54.

Haenlein M, Kaplan AM (2004). A beginner's guide to partial least squares analysis. Understanding Stat. 3:283-297. 
Hofgaard A, Tardif J, Bergeron Y (1999). Dendroclimatic response of Picea mariana and Pinus banksiana along a latitudinal gradient in the eastern Canadian boreal forest. Canadian J. Forest Res. 29: 13331346.

Jöreskog KG, Wold D (1982). The ML and PLS techniques for modeling with latent variable historical and comparative aspects. In: Jöreskog KG, Wold H (eds.), Systems under indirect observation: causality, structure, prediction. Amsterdam: North Holland. pp. 263-270.

Kozlowski TT, Pallardy SG (1997). Physiology of woody plants. 2nd edn. San Diego: Academic Press. pp. 1-6.

Maitra S, Yan J (2008). Principal component analysis and partial least squares: two dimension deduction techniques for regression. Casualty Actuarial Society Discussion Paper Program. pp. 79-90.

Mathes H (1993). Global optimization criteria of the PLS algorithm in recursive path models with latent variables. In: Haagen $\mathrm{K}$, Bartholomew DJ, Deistler M. (eds.), Statistical modeling and latent variables. Amsterdam: Elsevier. Pp. 229-248.

McDonald RP (1996). Path analysis with composite variables. Multivariate Behav. Res. 31:239-270.

Mevik BH, Cederkvist HR (2004). Mean Squared Error of Prediction (MSEP) estimates for Principal Component Regression (PCR) and Partial Least Squares Regression (PLSR). J.Chemom.18:422-429.

Phipps RL (1982). Comments on interpretation of climatic information from tree rings, eastern North America. Tree Ring Bull. 42:11-22.

R Core Team (2012). R: A language and environment for statistical computing. R Foundation for Statistical Computing, Vienna, Austria. ISBN 3-900051-07-0, URL http://www.R-project.org/.

Rodriguez-Nogales JM (2006). Approach to the quantification of milk mixtures by partial least-squares, principal component and multiple linear regression techniques. Food Chem. 98:782-789.
Schneewiss H (1993). Consistency at large in models with latent variables. In: Haagen K, Bartholomew DJ, Deistler M. (eds.), Statistical modeling and latent variables. Amsterdam: Elsevier. pp. 299-320.

Schweingruber FH, Briffa KR, Nogler P (1993). A tree-ring densitometric transect from Alaska to Labrador. Int. J. Biometeorol. 37:151-169.

Searson MJ, Thomas DS, Montagu KD, Conroy JP (2004). Wood density and anatomy of water limited eucalypts. Tree Physiol. 24:1295-1302.

Turnbull JW (1999). Eucalyptus plantations. New Forests 17:37-52.

Whitehead D, Jarvis PG. (1981). Coniferous forests and plantations. In: Kozlowski TT (ed.), Water deficits and plant growth. New York: Academic Press. pp. 50-153.

Wold H (1982). Soft modeling: the basic design and some extensions. In: Jöreskog KG, Wold H. (eds.), Systems under indirect observations : causality, structure, prediction. Amsterdam: North Holland. pp. 154.

Wold H (1985). Systems analysis by partial least squares. In: Nijkamp $\mathrm{P}$, Leitner $\mathrm{H}$, Wrigley $\mathrm{N}$ (eds.), Measuring the unmeasurable. Boston : Martinus Nijhoff. pp. 221-251.

Zweifel R, Ha"sler R (2001). Dynamics of water storage in mature subalpine Picea abies: temporal and spatial patterns of change in stem radius. Tree Physiol. 21:561-569.

Zweifel R, Zimmerman L, Zeugin F, Newbery DM.(2006). Intra-annual radial growth and water relations of trees: implication towards a growth mechanism. J. Exp. Bot. 57:1445-1459. 